\title{
Acute Management and Long-Term Survival Among Subjects With Severe Middle East Respiratory Syndrome Coronavirus Pneumonia and ARDS
}

\author{
Imran Khalid MD, Basem M Alraddadi MD, Youssef Dairi MD, Tabindeh J Khalid MD, \\ Mazen Kadri MD, Abeer N Alshukairi MD, and Ismael A Qushmaq MD
}

BACKGROUND: Data on the management, clinical course, and outcome of critical patients with Middle East Respiratory Syndrome coronavirus are scarce. We report here our experience and long-term outcome of such patients. METHODS: Subjects intubated for management of ARDS from Middle East Respiratory Syndrome coronavirus pneumonia and ARDS during the April-May 2014 outbreak were included. Their characteristics, ICU course, management, and outcome were evaluated. RESULTS: Fourteen subjects, including 3 health-care workers, met study criteria. Besides 2 health-care workers, all subjects had comorbidities. Predominant symptoms were fever, cough, and dyspnea. The worst median $\mathrm{P}_{\mathrm{aO}} / \mathrm{F}_{\mathrm{IO}_{2}}$ ratio of 118 post-intubation was seen on the third day, and median APACHE II score was 27. All subjects received lung-protective ventilation and $1 \mathrm{mg} / \mathrm{kg} / \mathrm{d}$ methylprednisolone infusion for ARDS. Eleven subjects received ribavirin and peginterferon $\alpha-2 a$. Subjects had a critical ICU course and required neuromuscular blockade $(n=11 ; 79 \%)$, required rescue therapy for respiratory failure $(n=8 ; 57 \%)$, developed shock $(n=10 ; 71 \%)$, and required renal replacement therapy $(n=8 ; 57 \%)$. Declining $C$-reactive protein levels correlated with clinical improvement despite continued positive real-time polymerase chain reaction results. Nine subjects died in ICU. Five subjects, including 3 health-care workers, were discharged from hospital and were alive after 1 y. CONCLUSIONS: Middle East Respiratory Syndrome coronavirus pneumonia with ARDS has high mortality in subjects with comorbidities. The mainstay of treatment is meticulous ARDS management. Those who survived the acute infection and its complications remained well after $1 \mathrm{y}$ in our study. The role of ribavirin and interferon warrants urgent further evaluation. Key words: Middle East Respiratory Syndrome coronavirus; acute respiratory distress syndrome (ARDS); pneumonia; respiratory failure. [Respir Care 2016;61(3):340-348. @ 2016 Daedalus Enterprises]

\section{Introduction}

In September 2012, the World Health Organization reported the first cases of pneumonia caused by the novel Middle East Respiratory Syndrome coronavirus, just a decade after the appearance of the highly pathogenic severe

\footnotetext{
The authors are affiliated with the King Faisal Specialist Hospital and Research Center, Jeddah, Saudi Arabia. Dr Khalid is also affiliated with the John D Dingell Veterans Affairs Medical Center, Detroit, Michigan.

Dr Khalid presented a version of this report at the American Thoracic Society 2015 International Conference, held May 15-20, 2015, in Denver, Colorado.
}

The authors have disclosed no conflicts of interest. acute respiratory syndrome coronavirus. The initial Middle East Respiratory Syndrome coronavirus cases have been postulated to have arisen as a result of camel-tohuman transmission. ${ }^{1}$ The later outbreaks, especially the one in 2014 seen in the city of Jeddah, Saudi Arabia, have been linked to health care-associated transmission. ${ }^{2}$ The rate of secondary transmission is low, ranging anywhere from $1-4 \% .^{3,4}$ However, those individuals who con-

Correspondence: Imran Khalid MD, King Faisal Specialist Hospital and Research Center, P.O. Box 40047, MBC J-102, Jeddah 21499, Saudi Arabia. E-mail: dr.imrankhalid@yahoo.com.

DOI: $10.4187 /$ respcare. 04325 
tacted the Middle East Respiratory Syndrome coronavirus infection did get significantly ill, with case fatality rates varying from 36 to $70 \%$ based on the underlying comorbidities and severity of pneumonia. ${ }^{2,4,5}$ As of August 21, 2015, 1,432 laboratory-confirmed cases of infection with Middle East Respiratory Syndrome coronavirus had been reported to the World Health Organization with cases from recent outbreaks in Korea and Saudi Arabia, including at least 507 related deaths, with no complete eradication of the virus in sight.

Until now there has been a lack of proven effective medications for therapy of Middle East Respiratory Syndrome coronavirus infection. Treatment remains mainly supportive with some therapies derived from the severe acute respiratory syndrome coronavirus experience and in vitro studies. ${ }^{6}$ A combination of antiviral therapy, methylprednisolone, and an immune modulator was used in severe acute respiratory syndrome coronavirus patients with varying success. ${ }^{7-9}$ In vitro studies on Middle East Respiratory Syndrome coronavirus showed that similar antiviral activity was exhibited by a combination of ribavirin and interferon. ${ }^{10}$ In an observational study, this combination was administered to 5 subjects with Middle East Respiratory Syndrome coronavirus, but all of the subjects eventually died. ${ }^{11}$ However, median time from admission to therapy was $19 \mathrm{~d}$, and it was unclear whether early administration of these agents would yield different results.

The mortality appears to be high in Middle East Respiratory Syndrome coronavirus patients who develop pneumonia and respiratory failure. Only 2 studies so far have focused on the clinical course and outcome of these patients. The first study was from a cluster of 12 suspected or confirmed cases with Middle East Respiratory Syndrome coronavirus pneumonia that were intubated with respiratory failure. Their mortality at $90 \mathrm{~d}$ was $58 \% .{ }^{4}$ In a second study of 8 subjects with Middle East Respiratory Syndrome coronavirus, subjects received a combination of interferon $2 \alpha$, ribavirin, and undefined usage of systemic steroids, therapies not used in the first study, and reported $75 \%$ mortality. ${ }^{12}$ None of the studies reported long-term outcome. We report here our experience and long-term outcome of subjects admitted to our intensive care unit during the 2014 Middle East Respiratory Syndrome coronavirus outbreak who were intubated for severe pneumonia, respiratory failure, and ARDS.

\section{Methods}

This was a retrospective study, and ethical approval was obtained from the institutional review board of the hospital.

\section{QUICK LOOK}

\section{Current knowledge}

Mortality of up to $70 \%$ in patients with Middle East Respiratory Syndrome coronavirus and pneumonia has been reported. The lack of definitive treatment and the development of severe ARDS make the management of these patients very challenging.

\section{What this paper contributes to our knowledge}

Subjects with Middle East Respiratory Syndrome coronavirus pneumonia and ARDS have a critical ICU course. Management should primarily focus on strict lung-protective ventilation. The role of ribavirin and interferon for Middle East Respiratory Syndrome coronavirus pneumonia should be evaluated in a randomized fashion. A decline in serial C-reactive protein levels correlates with clinical improvement. Subjects who survive the acute infection and its complications have a good prognosis.

\section{Study Site}

The study subjects were from the King Faisal Specialist Hospital and Research Center, Jeddah, which is a tertiary care hospital. It has an 18-bed medical ICU run by consultants who are North American board-certified in critical care and specialists (regional board-certified) who provide care under the consultants' supervision. The hospital is accredited by the Joint Commission International and Nurses Magnet Recognition Program. During the Middle East Respiratory Syndrome coronavirus outbreak, all confirmed or suspected Middle East Respiratory Syndrome coronavirus patients with respiratory failure were strictly admitted to the medical ICU, and in instances when the medical ICU was full, non-Middle East Respiratory Syndrome coronavirus patients were transferred to other ICUs in the hospital.

\section{Infection Control Practice}

The hospital did not have specific guidelines for Middle East Respiratory Syndrome coronavirus prevention before the index Middle East Respiratory Syndrome coronavirus case was diagnosed in the institution in early April 2014. However, immediately after the index case, strict infection control guidelines for Middle East Respiratory Syndrome coronavirus were enforced that included use of an N-95 mask, gown, and gloves in addition to standard hand hygiene. The medical ICU has only 2 negative-pressure rooms, so at times there were up to 8 patients with Middle East Respiratory Syndrome coronavirus pneumonia in non- 
negative-pressure ICU rooms. The staff inadvertently exposed to the index case were screened, and those with a positive screen were exempted from clinical duties until they cleared the virus.

\section{Subjects}

The main Middle East Respiratory Syndrome coronavirus outbreak in Jeddah Saudi Arabia occurred in AprilMay 2014 and constituted our study period. All patients 18 y or older with Middle East Respiratory Syndrome coronavirus pneumonia who required intubation for respiratory failure and ARDS were included in the study. We used the Berlin definition for ARDS. ${ }^{13}$ Diagnosis for Middle East Respiratory Syndrome coronavirus was made based on a single positive nasopharyngeal swab or tracheal aspirate obtained through the endotracheal tube with a realtime polymerase chain reaction. For confirmation, the realtime polymerase chain reaction targeted both the upstream E protein ( $u p E$ gene) and ORF1a as recommended at the time and reported in other studies..$^{1,2,4,12}$

\section{Treatment Strategy}

After the diagnosis of the index case of Middle East Respiratory Syndrome coronavirus pneumonia and ARDS in the medical ICU, a collaborative meeting was held between the infectious disease and ICU teams of the hospital. In the absence of concrete evidence, a consensus was reached, taking into consideration the available resources and local guidelines. It was decided to treat these subjects with a primary focus on lung-protective ventilation for ARDS by minimizing the tidal volumes, plateau pressures, and airway driving pressures. Moreover, a combination of ribavirin and peginterferon $\alpha$-2a was used in these critical subjects. A modified Meduri approach was also used. ${ }^{14}$ It comprised starting methylprednisolone infusion at $1 \mathrm{mg} / \mathrm{kg} / \mathrm{d}$ at the time of intubation and halving the dose at day 7 or earlier if there was significant clinical improvement in hypoxemia. After extubation, the steroids were gradually tapered over a few days rather than abruptly withdrawn.

\section{Outcome Measure}

Primary outcome was survival at $1 \mathrm{y}$ from the date of intubation. We also looked at ICU survival and 28- and 90-d survival along with ICU and hospital stay in these subjects.

\section{Data Collection}

Subjects' demographics, underlying comorbidities, symptoms, physical and radiological findings, laboratory
Table 1. Subject Demographics

\begin{tabular}{lc}
\hline \multicolumn{1}{c}{ Characteristic } & Value \\
\hline Age, median (range) y & $54(23-79)$ \\
Sex, $n$ & \\
Male & 9 \\
Female & 5 \\
BMI, median (range) $\mathrm{kg} / \mathrm{m}^{2}$ & $27.8(16-43)$ \\
Nationality, $n$ & \\
Saudi Arabian & 13 \\
Philippine & 1 \\
Comorbidities, $n$ (\%) & \\
Hypertension & $8(57)$ \\
Diabetes & $6(43)$ \\
Respiratory disease & $6(43)$ \\
Obesity & $6(43)$ \\
Congestive heart failure & $6(43)$ \\
Chronic kidney disease, without dialysis & $3(21)$ \\
Receiving chronic hemodialysis & $3(21)$ \\
Smoker & $3(21)$ \\
Ischemic heart disease & $2(14)$ \\
Receiving immunosuppressive medications & $2(14)$ \\
Stroke & $1(7)$ \\
& \\
\hline BMI = body mass index & \\
\hline
\end{tabular}

values, and respiratory and physiologic parameters while receiving mechanical ventilation were collected from electronic and paper medical records. These were collected at baseline, $24 \mathrm{~h}, 72 \mathrm{~h}, 1$ week, and 2 weeks of intubation. Subjects' severity of illness was measured on the day of intubation using APACHE II (Acute Physiology and Chronic Health Evaluation II) scores. Therapies received were also recorded. Cause of death in the subjects was also noted. Data were described using median and range for continuous variables and frequencies and percentages for categorical variables.

\section{Results}

During the study period, 32 patients were admitted to the medical ICU with pneumonia and respiratory failure. Of these, 14 were confirmed to have Middle East Respiratory Syndrome coronavirus pneumonia, met the criteria for ARDS, and were included in the study analyses. One patient with Middle East Respiratory Syndrome coronavirus was managed in ICU without invasive ventilation and was excluded. Demographics and baseline characteristics of the 14 study subjects are outlined in Table 1. Two subjects, both health-care workers, were completely healthy without any comorbidity. Fever, cough, and dyspnea were the most common features of the illness (Table 2).

Three subjects and 3 health-care workers acquired Middle East Respiratory Syndrome coronavirus infection 
Table 2. Clinical Characteristics

\begin{tabular}{|c|c|}
\hline Characteristic & Value \\
\hline \multicolumn{2}{|l|}{ Initial symptoms, $n(\%)$} \\
\hline Fever (temperature $>38^{\circ} \mathrm{C}$ ) & $14(100)$ \\
\hline Cough & $11(79)$ \\
\hline Dyspnea & $11(79)$ \\
\hline Vomiting & $3(21)$ \\
\hline Diarrhea & $3(21)$ \\
\hline Chest pain & $2(14)$ \\
\hline Sore throat & $2(14)$ \\
\hline Nausea & $2(14)$ \\
\hline Headache & $1(7)$ \\
\hline Myalgia & $1(7)$ \\
\hline Hemoptysis & $1(7)$ \\
\hline Abdominal pain & $1(7)$ \\
\hline \multicolumn{2}{|l|}{ Origin of exposure, $n(\%)$} \\
\hline Community/outside hospital & $8(57)$ \\
\hline Nosocomial exposure to admitted patient & $3(21)$ \\
\hline Nosocomial exposure to health care worker & $3(21)$ \\
\hline $\begin{array}{l}\text { Duration from symptoms to hospital admission, } \\
\text { median (range) } \mathrm{d}^{*}\end{array}$ & $3(1-7)$ \\
\hline $\begin{array}{l}\text { Duration from symptoms to ICU admission, } \\
\text { median (range) } \mathrm{d} \dagger\end{array}$ & $7(3-11)$ \\
\hline $\begin{array}{l}\text { Duration from symptoms to intubation, median } \\
\text { (range) } d\end{array}$ & $8(4-11)$ \\
\hline Noninvasive ventilation trial, $n$ & 2 \\
\hline APACHE II score, median (range) & $27(13-35)$ \\
\hline \multicolumn{2}{|l|}{$\begin{array}{l}\text { * Excluding } 3 \text { subjects with nosocomial infection. } \\
\dagger \text { Excluding } 1 \text { subject already in ICU. } \\
\text { APACHE II = Acute Physiology and Chronic Health Evaluation II }\end{array}$} \\
\hline
\end{tabular}

through nosocomial transmission. Health-care workers did not use personal protective equipment at the time of exposure from the undiagnosed index cases. Median time from ICU admission to intubation was $1 \mathrm{~d}$, and subjects were significantly ill at time of intubation with a median APACHE II score of 27 (Table 2).

Sensitivity of nasopharyngeal swab real-time polymerase chain reaction for diagnosis was $50 \%$ on initial and $71 \%$ on second testing in the study subjects. The tracheal aspirate real-time polymerase chain reaction did not have any false negative results in the cohort. Figure 1 outlines in detail the clinical course of these 14 subjects. The laboratory parameters are outlined in detail in Table 3 . The most common laboratory feature was lymphopenia in these subjects.

All subjects met the ARDS criteria within $72 \mathrm{~h}$ of intubation. Subjects were predominantly ventilated with volume control ventilation, with strict low tidal volumes and airway pressures. Nitric oxide was used as rescue therapy in 8 subjects (57\%) (Table 4). High-frequency oscillatory ventilation, prone positioning ventilation, and extracorporeal membrane oxygenation were not used. Eleven subjects $(79 \%)$ required neuromuscular blockade agents along with sedation very early in their ICU course. Neuromuscular blockers had to be started within $48 \mathrm{~h}$ of intubation for a median of $3 \mathrm{~d}$ to control ventilation in these 11 subjects.

A ribavirin (dose adjusted based on creatinine clearance) and peginterferon $\alpha$-2a combination was used in 11 subjects (79\%), started at a median of $6 \mathrm{~d}$ from the onset of symptoms, for a maximum of 2 weeks. At time of intubation, all 11 subjects were receiving this combination therapy. In 2 subjects, the combination of drugs was discontinued earlier because of significant improvement in hypoxemia (Table 5). All of the survivors received this combination.

Subjects received empiric broad-spectrum antibiotics, which were discontinued if the finalized cultures were negative. Oseltamivir was empirically started in 50\% of the subjects and was discontinued later after confirmation of Middle East Respiratory Syndrome coronavirus and a negative influenza screen. During the clinical course, Creactive protein and procalcitonin testing were used as conjunctive measures along with serial cultures to help exclude secondary infections and progress of the disease. It was observed that improvement in C-reactive protein serum levels correlated with clinical improvement, especially decline in ventilator support and $\mathrm{F}_{\mathrm{IO}_{2}}$ requirements, although the real-time polymerase chain reaction for Middle East Respiratory Syndrome coronavirus would still be strongly positive.

Six subjects were extubated. However, one aspirated and was re-intubated and could not recover from the secondary insult. The remaining 5 , including 3 health-care workers, were successfully discharged from the hospital and are alive 1 y later (Table 6). Most of the subjects had improvement in their respiratory parameters initially but died because of underlying various comorbidities after a median of $19 \mathrm{~d}$ (range 12-34 d) from intubation. Of the 9 fatalities, 4 had unsuccessful cardiopulmonary resuscitation, and 4 had code status changed to "Do not attempt resuscitation."

\section{Discussion}

Our experience regarding patients with Middle East Respiratory Syndrome coronavirus pneumonia and ARDS is unique in many ways. First of all, in contrast to prior reports, all of our subjects were confirmed cases of Middle East Respiratory Syndrome coronavirus pneumonia and ARDS who were intubated and required invasive mechanical ventilation. Second, our cohort is the largest of such subjects. Third, we used a predetermined protocol of ribavirin and peginterferon $\alpha$-2a for Middle East Respiratory Syndrome coronavirus infection and methylprednisolone 


\section{ARDS and Middle East Respiratory Syndrome Coronavirus Pneumonia Management}

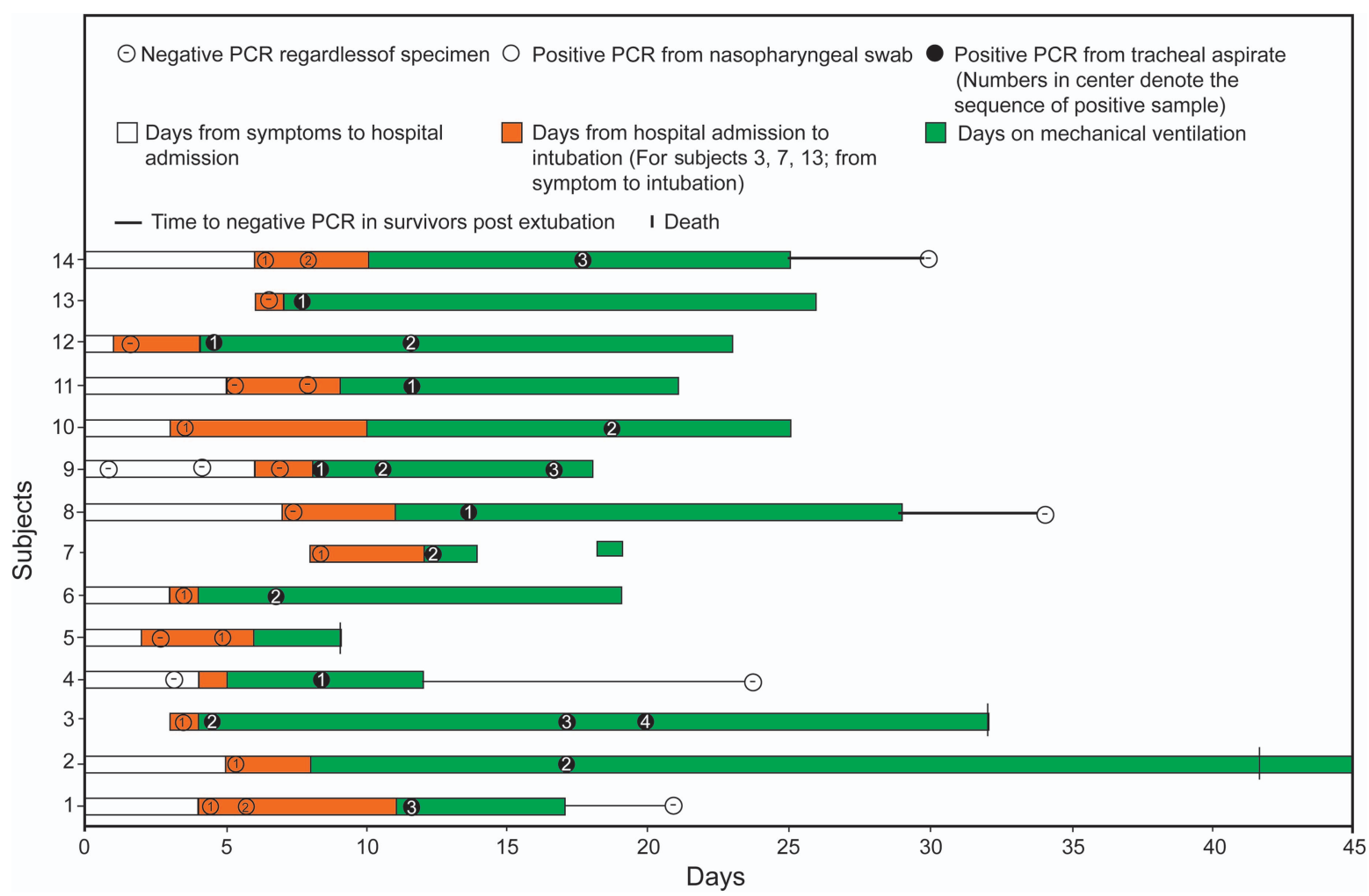

Fig. 1. Clinical course and outcome of the 14 subjects.

Table 3. Clinical and Laboratory Characteristics in ICU

\begin{tabular}{|c|c|c|c|c|c|}
\hline Characteristics & $\begin{array}{l}\text { At Hospital } \\
\text { Admission } \\
(n=14)\end{array}$ & $\begin{array}{c}24 \mathrm{~h} \text { After } \\
\text { Intubation } \\
(n=14)\end{array}$ & $\begin{array}{c}72 \mathrm{~h} \text { After } \\
\text { Intubation } \\
(n=14)\end{array}$ & $\begin{array}{l}1 \text { wk After } \\
\text { Intubation } \\
(n=11)\end{array}$ & $\begin{array}{l}2 \text { wks After } \\
\text { Intubation } \\
(n=10)\end{array}$ \\
\hline \multicolumn{6}{|l|}{ Clinical values, median (range) } \\
\hline Mean arterial pressure, $\mathrm{mm} \mathrm{Hg}$ & $71(57-117)$ & $70(52-122)$ & $69(51-116)$ & $85(66-119)$ & $62(58-109)$ \\
\hline Heart rate, beats/min & $89(54-151)$ & $99(52-172)$ & $103(57-190)$ & $98(50-155)$ & $97(51-152)$ \\
\hline \multicolumn{6}{|l|}{ Laboratory values, median (range) } \\
\hline WBC count $\times 10^{9}$ cells $/ \mathrm{L}$ & $9.1(2.9-17.3)$ & $8.6(2.5-16.1)$ & $5.5(1.5-14.1)$ & $8.2(2.5-12.5)$ & $8.1(5.2-17.5)$ \\
\hline Lymphocytes, \% (NR 20-45\%) & $13(1-22)^{*}$ & $9(1-15)^{*}$ & $6(0.5-11)^{*}$ & $5(1-9) \dagger$ & $7(6-10) *$ \\
\hline Platelets $\times 10^{9}$ cells/L (NR 155-435) & $229(51-741)$ & $215(45-763)$ & $176(6-729)$ & $138(52-546)$ & $194(45-402)$ \\
\hline Serum creatinine, $\mu \mathrm{mol} / \mathrm{L}$ (NR 60-105) & $90(31-994)$ & $101(35-797)$ & $78(40-680)$ & $84(44-410)$ & $93(42-390)$ \\
\hline Aspartate aminotransferase, units/L (NR 0-40) & $53(30-769)^{*}$ & $55(34-825)^{*}$ & $148(15-412)^{*}$ & $66(27-107)^{*}$ & $71(11-471)^{*}$ \\
\hline Alanine aminotransferase, units/L (NR 0-41) & $27(6-1,095)^{*}$ & $28(6-1,266)^{*}$ & $50(11-659)^{*}$ & $63(11-358)^{*}$ & $41(20-860)^{*}$ \\
\hline Total bilirubin, $\mu \mathrm{mol} / \mathrm{L}$ (NR $0-21$ ) & $6(5-51)$ & $6(4-54)$ & $7(4-49)$ & $12(4-77)$ & $16(5-118)$ \\
\hline Lactic acid, mmol/L (NR $0.5-2$ ) & $1.2(0.9-2.9) \dagger$ & $1.7(0.9-3.4)^{*}$ & $2.1(0.8-12) \dagger$ & $2(1-3.7) \ddagger$ & $2.1(0.9-6.4)^{*}$ \\
\hline \multicolumn{6}{|l|}{ Infections, $n$} \\
\hline Bacterial pneumonia & 0 & 0 & 1 & 1 & 1 \\
\hline Bloodstream infection & 1 & 1 & 0 & 0 & 1 \\
\hline Severe sepsis/septic shock & 0 & 1 & 2 & 2 & 1 \\
\hline $\begin{array}{l}\text { Missing 1-3 values. } \\
\dagger \text { Missing 4-6 values. } \\
\ddagger \text { Missing 7-8 values. } \\
\text { WBC }=\text { white blood cell } \\
\mathrm{NR}=\text { normal range }\end{array}$ & & & & & \\
\hline
\end{tabular}




\section{ARDS and Middle East Respiratory Syndrome Coronavirus Pneumonia Management}

Table 4. Ventilatory and Oxygenation Parameters in ICU

\begin{tabular}{|c|c|c|c|c|}
\hline Characteristics & $\begin{array}{l}24 \text { h After Intubation } \\
(n=14)\end{array}$ & $\begin{array}{c}72 \text { h After Intubation } \\
(n=14)\end{array}$ & $\begin{array}{c}1 \text { wk After Intubation } \\
(n=11)\end{array}$ & $\begin{array}{l}2 \text { wks After Intubation } \\
(n=10)\end{array}$ \\
\hline Volume control ventilation (CMV/PRVC), $n$ & 13 & 10 & 8 & 9 \\
\hline Pressure control ventilation, $n$ & 1 & 4 & 3 & 1 \\
\hline Usage of nitric oxide, $n$ & 2 & 7 & 4 & 1 \\
\hline Barotrauma, $n$ & 0 & 1 & 1 & 1 \\
\hline Breathing frequency, median (range) breaths/min & $26(24-38)$ & $29(23-36)$ & $28(22-35)$ & $30(19-39)$ \\
\hline $\mathrm{F}_{\mathrm{IO}_{2}}$, median (range) & $0.7(0.4-1)$ & $0.6(0.4-1)$ & $0.45(0.3-0.8)$ & $0.6(0.4-1)$ \\
\hline Tidal volume, median (range) $\mathrm{mL}$ & $370(200-490)$ & $368(220-480)$ & $370(300-400)$ & $375(280-400)$ \\
\hline PEEP, median (range) $\mathrm{cm} \mathrm{H}_{2} \mathrm{O}$ & $10(5-17)$ & $12(5-16)$ & $8(5-16)$ & $11(5-18)$ \\
\hline $\mathrm{PIP}$, median (range) $\mathrm{cm} \mathrm{H}_{2} \mathrm{O}$ & $28(19-41)$ & $27(22-47)$ & $25(14-32)$ & $31(21-43)$ \\
\hline Mean airway pressure, median (range) $\mathrm{cm} \mathrm{H}_{2} \mathrm{O}$ & $18(8-27)$ & $17(7-24)$ & $15(7-22)$ & $15(11-28)$ \\
\hline $\mathrm{pH}$, median (range) & $7.33(7.09-7.45)$ & $7.34(6.96-7.47)$ & $7.46(7.23-7.51)$ & $7.34(6.95-7.47)$ \\
\hline $\mathrm{P}_{\mathrm{aO}_{2}}$, median (range) $\mathrm{mm} \mathrm{Hg}$ & $74(73-180)$ & $71(32-128)$ & $77(68-128)$ & $79(60-120)$ \\
\hline $\mathrm{P}_{\mathrm{aCO}_{2}}$, median (range) $\mathrm{mm} \mathrm{Hg}$ & $51(28-95)$ & $52(32-89)$ & $48(33-79)$ & $50(43-141)$ \\
\hline $\mathrm{P}_{\mathrm{aO}_{2}} / \mathrm{F}_{\mathrm{IO}_{2}}$, median (range) & $159(70-245)$ & $118(49-205)$ & $170(85-255)$ & $147(60-266)$ \\
\hline Oxygenation index, median (range) & $22(7-32)$ & $19(5-33)$ & $9(5-29)$ & $11(7-34)$ \\
\hline Bicarbonate, median (range) $\mathrm{mmol} / \mathrm{L}$ & $21(18-49)$ & $25(15-33)$ & $33(25-38)$ & $26(21-32)$ \\
\hline $\begin{array}{l}\mathrm{PRVC}=\text { pressure-regulated volume control } \\
\mathrm{PIP}=\text { peak inspiratory pressure } \\
\mathrm{CMV}=\text { continuous mandatory ventilation }\end{array}$ & & & & \\
\hline
\end{tabular}

infusion for ARDS in a modified Meduri approach. Fourth, we had 2 subjects in the cohort who were perfectly healthy and were intubated for severe pneumonia and ARDS from Middle East Respiratory Syndrome coronavirus. Finally, we followed the survivors for $1 \mathrm{y}$ and report long-term survival in these subjects, something not reported before.

The common clinical characteristics of fever, cough, and dyspnea in our subjects and their duration from symptoms to intubation were similar to those described in other Middle East Respiratory Syndrome coronavirus reports. ${ }^{4,12,15,16}$ As compared with severe acute respiratory syndrome patients, myalgias were not as common. The first 2 subjects were given a trial of noninvasive ventilation, and after its failure, none of the other subjects with suspected Middle East Respiratory Syndrome coronavirus were given such a trial. Our experience is similar to earlier reports, and noninvasive ventilation should not be attempted in patients with Middle East Respiratory Syndrome coronavirus., ${ }^{41}$

Lung-protective ventilation is the mainstay of treatment for ARDS patients. We were able to ventilate our subjects with conventional modes of ventilation. The median tidal volume of $370 \mathrm{~mL}(6.3 \mathrm{~mL} / \mathrm{kg}$ ideal body weight $)$ in our subjects was lower than what has been reported in earlier studies. ${ }^{4,12} \mathrm{We}$ did use inhaled nitric oxide in $57 \%$ of the subjects as rescue therapy because it helps to improve oxygenation and was less of a safety risk for the staff. ${ }^{17}$ This enabled us to control the oxygenation without driving up the airway pressures. We did not use early high-frequency oscillatory ventilation in our subjects because recent data in ARDS show no benefit. ${ }^{18,19}$ The reason for not using it as rescue therapy was because of the aerosol generation and increased risk of disease transmission. ${ }^{20} \mathrm{Be}-$ cause at any given time, the number of subjects with Middle East Respiratory Syndrome coronavirus exceeded the number of negative-pressure medical ICU rooms, the risk that high-frequency oscillatory ventilation posed to staff outweighed the benefit. Moreover, using 2 rescue therapies is not supported in the literature. Extracorporeal membrane oxygenation was not used because we were able to control oxygenation and ventilation in our subjects by conventional means, and the 2 subjects who died with refractory hypoxemia were not candidates for extracorporeal membrane oxygenation. We used intravenous sedation in all subjects and neuromuscular blockers in 11 subjects. The neuromuscular blockers were started within $48 \mathrm{~h}$ of intubation, more so due to necessity, and every attempt was made to discontinue them as soon as possible. Recent data in moderate to severe ARDS favor the early use of neuromuscular blockers. ${ }^{21}$ Prone positioning was not attempted due to lack of expertise of the staff and the risk it posed to them, especially in subjects admitted to nonnegative-pressure ICU rooms.

The use of ribavirin and interferon as treatment for Middle East Respiratory Syndrome coronavirus infection had been postulated before the outbreak occurred in our hospital. A recently published study that used the same regimen reported favorable 14-d survival. ${ }^{22}$ Due to the limited number of subjects and lack of a control group in our study, we cannot make a conclusion about the use of this combination for Middle East Respiratory Syndrome coro- 
Table 5. Therapies Used and Outcome Measures

\begin{tabular}{|c|c|}
\hline Variable & $\begin{array}{l}\text { Result ( } n=14 \text { Unless } \\
\text { Otherwise Specified) }\end{array}$ \\
\hline $\begin{array}{l}\text { Duration of mechanical ventilation, median } \\
\quad \text { (range) } d\end{array}$ & $16(3-32)$ \\
\hline Use of neuromuscular blockade, $n(\%)$ & $11(79)$ \\
\hline $\begin{array}{l}\text { Initiation of neuromuscular blockade } \\
\text { post-intubation, median (range) } \mathrm{h}\end{array}$ & $26(7-47)$ \\
\hline $\begin{array}{l}\text { Time receiving neuromuscular blockade, } \\
\text { median (range) d }\end{array}$ & $3(1-13)$ \\
\hline $\begin{array}{l}\text { Use of methylprednisolone infusion } \\
\text { (modified Meduri), } n(\%)\end{array}$ & $14(100)$ \\
\hline Use of nitric oxide as rescue therapy, $n(\%)$ & $8(57)$ \\
\hline Tracheostomy, $n(\%)$ & $1(7)$ \\
\hline Use of ribavirin and peginterferon $\alpha-2 \mathrm{a}, n(\%)$ & $11(79)$ \\
\hline $\begin{array}{l}\text { Time from symptoms to initiation of ribavirin } \\
\text { and peginterferon } \alpha \text {-2a, median (range) } \mathrm{d} \\
\quad(n=11)\end{array}$ & $6(1-13)$ \\
\hline Renal replacement therapy, $n(\%)$ & $8(57)$ \\
\hline Use of vasopressor agents, $n(\%)$ & $12(86)$ \\
\hline Developed shock, $n(\%)$ & $10(71)$ \\
\hline ICU length of stay, median (range) $d$ & $17(3-37)$ \\
\hline Hospital length of stay, median (range) d & $22(3-74)$ \\
\hline ICU death, $n(\%)$ & $9(64)$ \\
\hline Alive at $28 \mathrm{~d}, n(\%)$ & $8(57)$ \\
\hline Alive at $90 \mathrm{~d}$ and $1 \mathrm{y}, n(\%)$ & $5(36)$ \\
\hline Full code at ICU admission, $n(\%)$ & $14(100)$ \\
\hline \multicolumn{2}{|l|}{ Code status at death $(n=9), n(\%)$} \\
\hline Full code & $4(44)$ \\
\hline DNAR & $5(55)$ \\
\hline $\begin{array}{l}\text { Time to death from DNAR decision, median } \\
\quad \text { (range) } \mathrm{h}(n=5)\end{array}$ & $22(5-51)$ \\
\hline
\end{tabular}

navirus infection. Whether interferon $\beta$ could be a better replacement for peginterferon $2 \alpha$ also remains to be seen. ${ }^{23}$ These treatment combinations need to be evaluated in a prospective randomized manner.

The use of corticosteroids in viral pneumonia and ARDS is controversial. Nonetheless, the use of low dose methylprednisolone has been associated with improved mortality and morbidity outcomes without increased adverse reactions in subjects with ARDS. ${ }^{24}$ We used this approach in our subjects with special emphasis on not withdrawing the steroids abruptly after extubation. We would leave their usage to the discretion of the treating physicians.

With our combination of lung-protective ventilation, neuromuscular blockade, and low-dose steroids, we were able to oxygenate and ventilate all but 2 of our subjects. The one subject who died within $2 \mathrm{~d}$ of intubation with refractory hypoxemia also had a superimposed pulmonary embolism that contributed to failure of therapy. Another subject died of refractory hypoxemia due to aspiration pneumonia later in the course, unrelated to initial Middle East Respiratory Syndrome coronavirus infection.

Acute kidney injury requiring renal replacement therapy occurred in 5 subjects (36\%) in addition to the 3 subjects who were already receiving hemodialysis. This is less than the 58\% that is reported in a prior Middle East Respiratory Syndrome coronavirus case series. ${ }^{4}$ Development of kidney injury in the ICU depends on many factors, including severity of shock, drug adverse effects, and underlying comorbidities, and could explain the difference in a small cohort of subjects.

We used aggressive broad-spectrum antibiotics and sequential cultures to guide the type and duration of antibiotics. We also measured serum C-reactive protein levels. A decline in C-reactive protein levels correlated very well with clinical improvement in terms of declining $\mathrm{F}_{\mathrm{IO}_{2}}$ requirements and ventilator support. The real-time polymerase chain reaction done on tracheal aspirates of the subjects, however, remained strongly positive for Middle East Respiratory Syndrome coronavirus and trailed clinical improvement and the decline in C-reactive protein levels. It is possible that the use of methylprednisolone decreased the viral clearance in these subjects. ${ }^{25}$ However, this delayed clearance in our observations did not translate into continued infectivity in these subjects. It is likely that the individual immune response of these subjects resulted in the development of antibodies to Middle East Respiratory Syndrome coronavirus. These antibodies plausibly overcame the effect of the viral load and led to clinical improvement of the subjects despite strongly positive realtime polymerase chain reaction results. ${ }^{26}$ It is also possible that these antibodies helped in clearance of viremia.

We had 3 subjects and 3 health-care workers with nosocomial Middle East Respiratory Syndrome coronavirus infection. However, this transmission occurred before the diagnosis of the index cases. Once the index cases of Middle East Respiratory Syndrome coronavirus were diagnosed, strict infection control guidelines for Middle East Respiratory Syndrome coronavirus were implemented, and no new nosocomial or health-care worker transmission occurred. Moreover, even from subjects with Middle East Respiratory Syndrome coronavirus who were admitted to non-negative-pressure ICU rooms, when the number of cases exceeded the available capacity, there was no nosocomial transmission.

Two health-care workers in our population were completely healthy before the Middle East Respiratory Syndrome coronavirus infection. Although the case series by Al-Hameed et al $^{12}$ reports 1 healthy person who had Middle East Respiratory Syndrome pneumonia, it is unclear whether that person required intubation and invasive ventilation. We excluded such subjects from our study. The fact that 2 completely healthy individuals developed 


\section{ARDS and Middle East Respiratory Syndrome Coronavirus Pneumonia Management}

Table 6. Comorbidities and Cause of Death in 9 Middle East Respiratory Syndrome Fatalities

\begin{tabular}{lcll}
\hline \hline $\begin{array}{c}\text { Intubation to } \\
\text { Death, d }\end{array}$ & $\begin{array}{c}\text { Subject No. } \\
\text { (From Fig. 1) }\end{array}$ & Comorbidities & Cause of Death \\
\hline 2 & 7 & Acute pulmonary embolism & Refractory hypoxemia \\
3 & 5 & ESKD, preexisting line sepsis & Septic shock \\
12 & 11 & $\begin{array}{l}\text { Pancreatic cancer, end-stage COPD, severe cardiomyopathy (EF 20\%) } \\
\text { Multiorgan system failure }\end{array}$ & Cardiogenic shock \\
15 & 6 & Severe cardiomyopathy (EF 10\%) & Liver failure \\
15 & 10 & Cirrhosis, COPD, peritonitis & Ventilator-associated pneumonia \\
19 & 12 & ESKD, stroke, COPD, gastrointestinal bleeding & Septic shock \\
19 & 13 & Paraplegic, cardiomyopathy (EF 30\%), neurogenic bladder with urinary tract & Septic shock \\
& & infection & Refractory hypoxemia \\
28 & 3 & ESKD, cardiomyopathy (EF 30\%), interstitial lung disease &
\end{tabular}

such severe ARDS is also unique in our report and indicates the extreme caution.

Most of the subjects experienced improvement in their respiratory parameters initially. Non-survivors died because of underlying comorbidities and secondary infections, mainly from sepsis and shock-related complications. It is possible that the Middle East Respiratory Syndrome coronavirus infection or the treatments used for it made these subjects more susceptible to secondary infection. This should be taken into consideration while caring for Middle East Respiratory Syndrome coronavirus-infected patients.

\section{Conclusion}

Middle East Respiratory Syndrome coronavirus pneumonia with ARDS has a very high mortality. The severe disease progression usually occurs in patients with underlying comorbidities; however, completely healthy persons are also susceptible. Nosocomial transmission can be avoided using personal protective gear, even for patients who are not admitted to negative-pressure rooms. The treatment remains supportive and should focus mainly on lungprotective ventilation. Those who survived the acute infection and its complications remained well after $1 \mathrm{y}$ in our study. The role of ribavirin and interferon for Middle East Respiratory Syndrome coronavirus pneumonia should be evaluated in a randomized fashion in future cases because the disease is still active in parts of the Middle East and can again become a cause of international concern.

\section{ACKNOWLEDGMENTS}

We thank all of the staff, including nursing, respiratory therapists, physicians, housekeepers, in-patient officers, and administrative and leadership staff, at the King Faisal Specialist Hospital and Research Center,
Jeddah, for their untiring efforts and commitment to patient care during the Middle East Respiratory Syndrome coronavirus outbreak.

\section{REFERENCES}

1. Azhar EI, El-Kafrawy SA, Farraj SA, Hassan AM, Al-Saeed MS, Hashem AM, Madani TA. Evidence for camel-to-human transmission of MERS coronavirus. N Engl J Med 2014;370(26):2499-2505.

2. Oboho IK, Tomczyk SM, Al-Asmari AM, Banjar AA, Al-Mugti H, Aloraini MS, et al. 2014 MERS-CoV outbreak in Jeddah-a link to health care facilities. N Engl J Med 2015;372(9):846-854.

3. Drosten C, Meyer B, Müller MA, Corman VM, Al-Masri M, Hossain $\mathrm{R}$, et al. Transmission of MERS-coronavirus in household contacts. N Engl J Med 2014;371(9):828-835.

4. Arabi YM, Arifi AA, Balkhy HH, Najm H, Aldawood AS, Ghabashi A, et al. Clinical course and outcomes of critically ill patients with Middle East respiratory syndrome coronavirus infection. Ann Intern Med 2014;160(6):389-397.

5. Saad M, Omrani AS, Baig K, Bahloul A, Elzein F, Matin MA, et al. Clinical aspects and outcomes of 70 patients with Middle East respiratory syndrome coronavirus infection: a single-center experience in Saudi Arabia. Int J Infect Dis 2014;29:301-306.

6. Al-Tawfiq JA, Memish ZA. What are our pharmacotherapeutic options for MERS-CoV? Expert Rev Clin Pharmacol 2014;7(3):235238.

7. Tsang KW, Ho PL, Ooi GC, Yee WK, Wang T, Chan-Yeung M, et al. A cluster of cases of severe acute respiratory syndrome in Hong Kong. N Engl J Med 2003;348(20):1977-1985.

8. Sung JJ, Wu A, Joynt GM, Yuen KY, Lee N, Chan PK, et al. Severe acute respiratory syndrome: report of treatment and outcome after a major outbreak. Thorax 2004;59(5):414-420.

9. Mazzulli T, Kain K, Butany J. Severe acute respiratory syndrome: overview with an emphasis on the Toronto experience. Arch Pathol Lab Med 2004;128(12):1346-1350.

10. Chan JF, Chan KH, Kao RY, To KK, Zheng BJ, Li CP, et al. Broad-spectrum antivirals for the emerging Middle East respiratory syndrome coronavirus. J Infect 2013;67(6):606-616.

11. Al-Tawfiq JA, Momattin H, Dib J, Memish ZA. Ribavirin and interferon therapy in patients infected with the Middle East respiratory syndrome coronavirus: an observational study. Int J Infect Dis 2014; 20:42-46.

12. Al-Hameed F, Wahla AS, Siddiqui S, Ghabashi A, Al-Shomrani M, Al-Thaqafi A, et al. Characteristics and outcomes of Middle East 


\section{ARDS and Middle East Respiratory Syndrome Coronavirus Pneumonia Management}

respiratory syndrome coronavirus patients admitted to an intensive care unit in Jeddah, Saudi Arabia. J Intensive Care Med 2015;pii: 0885066615579858. [Epub ahead of print]

13. ARDS Definition Task Force, Ranieri VM, Rubenfeld GD, Thompson BT, Ferguson ND, Caldwell E, et al. Acute respiratory distress syndrome: the Berlin definition. JAMA 2012;307(23):2526-2533.

14. Meduri GU, Golden E, Freire AX, Taylor E, Zaman M, Carson SJ, et al. Methylprednisolone infusion in early severe ARDS: results of a randomized controlled trial. Chest 2007;131(4):954-963.

15. Assiri A, McGeer A, Perl TM, Price CS, Al Rabeeah AA, Cummings DA, et al. Hospital outbreak of Middle East respiratory syndrome coronavirus. N Engl J Med 2013;369(5):407-416.

16. Alghamdi IG, Hussain II, Almalki SS, Alghamdi MS, Alghamdi MM, El-Sheemy MA. The pattern of Middle East respiratory syndrome coronavirus in Saudi Arabia: a descriptive epidemiological analysis of data from the Saudi Ministry of Health. Int J Gen Med 2014;7:417-423.

17. Teman NR, Thomas J, Bryner BS, Haas CF, Haft JW, Park PK, et al. Inhaled nitric oxide to improve oxygenation for safe critical care transport of adults with severe hypoxemia. Am J Crit Care 2015; 24(2):110-117.

18. Ferguson ND, Cook DJ, Guyatt GH, Mehta S, Hand L, Austin P, et al. High-frequency oscillation in early acute respiratory distress syndrome. N Engl J Med 2013;368(9):795-805.

19. Young D, Lamb SE, Shah S, MacKenzie I, Tunnicliffe W, Lall R, et al. High-frequency oscillation for acute respiratory distress syndrome. N Engl J Med 2013;368(9):806-813.
20. Tran K, Cimon K, Severn M, Pessoa-Silva C, Conly J. Aerosolgenerating procedures and risk of transmission of acute respiratory infections: a systematic review. CADTH Technol Overv 2013;3(1): e3201.

21. Papazian L, Forel JM, Gacouin A, Penot-Ragon C, Perrin G, Loundou A, et al. Neuromuscular blockers in early acute respiratory distress syndrome. N Engl J Med 2010;363(12):1107-1116.

22. Omrani AS, Saad MM, Baig K, Bahloul A, Abdul-Matin M, Alaidaroos AY, et al. Ribavirin and interferon $\alpha$-2a for severe Middle East respiratory syndrome coronavirus infection: a retrospective cohort study. Lancet Infect Dis 2014;14(11):1090-1095.

23. Shalhoub S, Farahat F, Al-Jiffri A, Simhairi R, Shamma O, Siddiqi $\mathrm{N}$, Mushtaq A. IFN- $\alpha 2$ a or IFN- $\beta 1 \mathrm{a}$ in combination with ribavirin to treat Middle East respiratory syndrome coronaviruspneumonia: a retrospective study. J Antimicrob Chemother 2015;70(7):2129-2132.

24. Tang BM, Craig JC, Eslick GD, Seppelt I, McLean AS. Use of corticosteroids in acute lung injury and acute respiratory distress syndrome: a systematic review and meta-analysis. Crit Care Med 2009;37(5):1594-1603.

25. Lee N, Allen Chan KC, Hui DS, Ng EK, Wu A, Chiu RW, et al. Effects of early corticosteroid treatment on plasma SARS-associated coronavirus RNA concentrations in adult patients. J Clin Virol 2004; 31(4):304-309.

26. Spanakis N, Tsiodras S, Haagmans BL, Raj VS, Pontikis K, Koutsoukou A, et al. Virological and serological analysis of a recent Middle East respiratory syndrome coronavirus infection case on a triple combination antiviral regimen. Int J Antimicrob Agents 2014; 44(6):528-532. 